\title{
A GEOGRAFIA RELIGIOSA DOS TERREIROS DE CANDOMBLÉ DE CONTAGEM, MINAS GERAIS
}

THE GEOGRAPHY OF RELIGIOUS CANDOMBLÉ CONTAGEM, MinAS GERAIS

AURINo JosÉ Góıs ${ }^{*}$ )

\begin{abstract}
RESUMO
O texto apresenta uma análise geográfica do uso ritualístico dos terreiros de candomblé de áreas específicas que se estendem para além de seu espaço sagrado propriamente dito. A explicação dessa ocorrência vai se apoiar na compreensão de que a expansão territorial desse espaço sagrado é uma práxis inerente ao fazer religioso dessa religião, compreendendo, por sua vez, o território como um espaço vivido e apropriado afetiva e simbolicamente. Os dados foram obtidos a partir de uma pesquisa mais ampla sobre os terreiros da cidade de Contagem no período de 2009 a 2010 e sua análise será realizada desde a perspectiva da geografia humanista cultural, que tem a geografia da religião como um campo de investigação. Esse estudo aponta ao final a estreita relação entre os atos litúrgicos dessa religião e a natureza, denotando a necessidade de proximidade e preservação das áreas verdes de seu entorno como garantia de manutenção de seu patrimônio imaterial no futuro.
\end{abstract}

Palavras-Chave: Geografia da Religião. Território. Espaço Sagrado Expandido. Rituais.

\begin{abstract}
The paper presents an analysis of the geographical ritualistic use of Candomble specific areas that extend beyond its sacred space itself. The explanation of this occurrence will assist in understanding the territorial expansion of that sacred space is a religious praxis inherent to this religion, comprising, in turn, the territory as a lived space and appropriate affective and symbolically. Data were obtained from a broader study about the yards of the city of Count in the period 2009-2010 and its analysis will be performed from the perspective of humanistic cultural geography, which has the geography of religion as a field of research. This study points to the end of the close relationship between this religion and liturgical nature, denoting the need for closeness and preservation of green areas of your surroundings as a guarantee of maintaining its intangible heritage in the future.
\end{abstract}

KEYWORDS: Geography of Religion. Territory. Sacred Space Expanded. Rituals.

\section{INTRODUÇÃO}

Este trabalho é parte de uma pesquisa mais ampla sobre o mapeamento das religiões de matrizes africanas em Contagem, na região metropolitana de Belo Horizonte (GOIS, 2011). Quando essa pesquisa foi iniciada em 2009 ainda não tinha sido realizado o mapeamento financiado pelo Governo Federal através do Ministério do Desenvolvimento Social e Combate a Fome iniciado em 2010 e concluído em 2011. O que a pesquisa encontrou foi um inventário dessas religiões em Belo Horizonte realizado em 2003 pela Prefeitura, através da

(*) Doutor em Geografia - Tratamento da Informação Espacial pela Pontifícia Universidade Católica de Minas Gerais - PUC Minas, com tese a respeito do espaço e território das religiões de matrizes africanas. Professor Adjunto IV do Departamento de Ciências da Religião e membro do Comitê de Ética da Pró-Reitoria de Pesquisa e Pós-Graduação da mesma instituição. Coordenador de Extensão do Curso de Engenharia Mecânica e Coordenador do Programa Espaço, Dignidade e Cidadania, ambos em Contagem. E-mail: aurino.puc@gmail.com 
Secretaria Municipal de Cultura, financiada pelo Ministério da Justiça - Fundo de Direitos Difusos. Na ocasião foram identificadas cento e oitenta e sete comunidades religiosas entre candomblés, umbanda e reinados ( $\mathrm{PBH}, 2003)$. Teve-se conhecimento também de um levantamento semelhante com recursos da Fundação Palmares, realizado pelo CENARAB - Centro Nacional de Africanidade e Resistência Afro-Brasileira, mas não foi permitido na época o acesso a esse material. Buscou-se também na Federação Espírita Umbandista informações, mas estavam desatualizadas. Desse modo, a pesquisa iniciou a coleta de dados diretamente no campo a partir de alguns terreiros indicados por adeptos dessas religiões que, por sua vez, indicavam outros, resultando ao final na identificação de cinquenta e cinco terreiros. Todavia, foram selecionados apenas trinta e seis. Essa seleção foi decorrente de vários fatores, tais como o interesse e agenda das lideranças e o tempo disponível para a realização da investigação.

A cidade de Contagem foi escolhida por ser a segunda cidade do Estado em população e a quarta em relação ao Produto Interno Bruto do Estado (FJP, 2009), e também por não ter até àquele momento um estudo dessa natureza.

Embora inédito em seu início, no que diz respeito a Contagem, esse tipo de pesquisa já tinha sido realizada em outras cidades, atendendo objetivos de outra natureza. Este é o caso do mapeamento iniciado em 2006 e concluído em 2008, na cidade de Salvador, realizado pela Secretaria Municipal da Reparação em parceria com o Centro de Estudos Afro-Orientais - CEAO, da Universidade Federal da Bahia, sob a coordenação do antropólogo Jocélio Teles dos Santos (SANTOS 2008). Esse mapeamento teve como finalidade última a legalização e regularização fundiária das comunidades religiosas pesquisadas. O mapeamento proposto neste trabalho teve como objetivo verificar o modo de apropriação espacial dessas comunidades de seus territórios.

\section{A GEOGRAFIA DA RELIGIÃO}

A geografia da religião toma sua forma objetiva na religião que detém o poder de ministrar os ritos e manipular os símbolos de seu culto. De acordo com Zeny Rosendahl (2002, p.14), "a geografia da religião, concentrando-se no componente religioso, investiga, primeiro, a interação espacial entre uma cultura e seu ambiente terrestre complexo; segundo, a situação espacial entre diferentes culturas." Sendo assim, este trabalho que estuda os territórios sagrados de matriz africana na cidade de Contagem constitui-se num trabalho de geografia da religião, pois almeja compreender a interação dos Templos afro-brasileiros na espacialidade urbana desta cidade. 
O sagrado é uma experiência fundamental, constitutiva do humano e sua expressividade objetiva - a religião; é um aspecto indissociável da vida. Para a geografia da religião interessa menos a instituição religiosa e mais o universo simbólico que imprime na paisagem a sua marca característica. Desse modo, "os geógrafos devem se interessar pelos aspectos da vida, tais como imagem e simbolismo, valor e significado, uma vez que a religião é um aspecto da vida que permite a investigação desses temas." (RosendAHL, 2002, p.16) Assim, cabe aos geógrafos da religião a tarefa de explorar o universo das representações mentais, bem como compreender como essas representações se inserem na paisagem e na organização do espaço.

A religião nem sempre recebeu a devida atenção no pensamento geográfico. Esse "esquecimento" pode ser explicado pelos matizes ideológicos sob os quais se sustentaram as correntes e escolas da geografia no decorrer do tempo. Um desses matizes, por exemplo, foi o positivismo. Para esse matiz filosófico, tudo que transcende o plano dos sentidos é inacessível ao conhecimento humano e, portanto, não demonstrável. Ora, a existência de uma realidade transcendente objeto direto das religiões - constitui-se em uma questão metafísica, fora do âmbito da ciência positiva. De outro modo, a matiz materialista - base de sustentação da Geografia Crítica - levou os geógrafos críticos a marginalizar as questões religiosas de seus estudos. Entretanto, a Geografia Humanista Cultural, ao contemplar a dimensão subjetiva e a experiência vivida dos indivíduos e grupos sociais, possibilitou uma reflexão do fenômeno religioso na geografia.

Para Rosendahl, os estudos da religião na geografia podem ser classificados em dois grandes blocos: antes de 1970, quando os estudos contemplam os efeitos da religião sobre a paisagem, sem considerar os valores morais e afetivos; e, pós 1970, quando a perspectiva humanista, busca desvendar as fontes das sensações vividas pelo homem e pelos grupos sociais. Segundo Gil Filho, o tema da religião na geografia comporta duas abordagens: a geografia religiosa, focada na influência da religião na percepção do homem sobre o mundo e a humanidade, que essencialmente concerne ao âmbito teológico e cosmológico; e a geografia da religião, que analisa os efeitos das múltiplas relações da religião com a sociedade, a cultura e o ambiente (GIL FILHO, 2008 p. 12). Este trabalho se insere nessa última abordagem.

A geografia da religião é uma perspectiva da geografia que procura responder a questão do lugar do homem no espaço vivido, a partir de sua dimensão espiritual, enquanto existência significada, ou seja, existência de sentido. Desse modo, uma geografia da religião não deverá se ocupar tanto das instituições religiosas tarefa mais propícia à sociologia - mas do sagrado que configura o espaço vivido de um determinado lugar como lugar de sentido para as pessoas que nele coabitam. 
A geografia da religião busca assim situar o homem no mundo vivido - tarefa de toda a geografia - na perspectiva de sua dimensão espiritual, entendida como o sentido dado ao seu lugar no mundo, numa relação de transcendência, como resposta à sua finitude existencial, sem perder a conexão dialógica com as outras dimensões da existência humana. Em outras palavras, a geografia da religião é a mesma e única geografia sob a perspectiva privilegiada do sagrado.

Se esse postulado estiver correto, de que a geografia é a ciência da presença e ação dos seres humanos situados no mundo e se se considerar que toda ação humana é cultural, uma vez que sua comunicação e compreensão estão circunscritas numa linguagem e num sistema simbólico específico, pode-se então concluir que toda análise geográfica é situada culturalmente. O que interessa aqui nesse momento é a posição cultural dos grupos religiosos de matriz africana em Contagem ou, em outras palavras, o seu território sagrado.

\section{O CONCEITO DE TERRITÓRIO}

A noção de território pode ser compreendida a partir do pressuposto de que todo ser humano é um ser situado no mundo. Ele está situado na Terra, a casa planetária de todos os viventes. Assim, a noção de território implica em saber onde está um grupo ou determinado sujeito e qual o alcance de sua presença a partir desta posição. Todavia, um sujeito ou grupo não está em todo o planeta, mas numa porção delimitada dele. Esta porção é o seu território. Sendo assim, pode-se afirmar que o território está diretamente relacionado ao alcance das ações dos homens ou de grupos humanos situados numa determinada posição deste solo planetário. Deste modo, as ações humanas são sempre ações espaciais, por serem situadas, e também temporais, por serem apreendidas na forma sucessiva do antes, agora e depois, ou seja, do passado, presente e futuro. Em suma, o homem é um ser situado no espaço e no tempo e todas as suas ações só podem ser compreendidas nesses limiares.

Com efeito, ao agir no mundo o ser humano estabelece pontos de referência ou marcos delimitadores a partir do lugar em que está situado que vem a ser o lugar onde nasceu, o lugar onde habita. A geografia é o campo de saber por excelência que ajuda o homem na realização desta tarefa existencial, a de se situar no espaço e no tempo. De acordo com Pinchemel, "a geografia é o meio pelo qual o homem realiza sua existência, enquanto que a Terra é uma possibilidade essencial de seu destino." (PInCHEMEL, 1990, "avant-propos" apud AMORIM FILHO, 2007, p. 25). 
Os marcos delimitadores, a partir dos quais o homem se situa no mundo, com o tempo irão se constituir em referenciais identitários para ele em particular e para o grupo em que está inserido na mesma experiência. Provavelmente este seja o pressuposto de alguns estudos para se pensar a territorialidade como a "multidimensionalidade do 'vivido' territorial" que se manifesta em "todas as escalas espaciais e sociais" (RAFFESTIN, 1983, p.158 e 161 apud SAHR, 2007, p. 59). Nessa afirmação está implícita a centralidade do ser humano como sujeito razoável, detentor de razão e liberdade, que irá inscrever seus interesses particulares e/ou de seu grupo na arena dialética de interesses diferenciados dos outros sujeitos ou grupos, consolidando numa mesma territorialidade, espacialidades distintas. Desse modo pode-se entender a afirmação de WolfDietrich Sahr, concordando com Haesbaert (2004, p.338), de que "um mesmo território pode ser definido por uma multiplicidade de ações (sejam elas espirituais ou corporais) resultando em espacialidades diferenciadas" (SAHR, 2007, p.59). Essa parece ser também a perspectiva de Icléia A. de Vargas quando afirma que "O território pode ser visto como espaço de articulação, de negociação [...], para onde confluem as ações, para onde convergem as rearticulações, abarcando aspectos objetivos e subjetivos das relações que nele se celebram. (VARGAS, 2007, p. 166).

O território, sendo multidimensional, pode ser apreendido tanto na expectativa de uma espacialidade em particular quanto na expectativa de espacialidades múltiplas a depender da natureza do objeto de análise e da ciência aliada ao estudo deste objeto. O desafio, portanto, no estudo do território, dada a sua multidimensionalidade, é o de apreendê-lo na sua complexidade e totalidade. Isto exigirá tanto um diálogo multidisciplinar quanto uma base filosófica que consiga agrupar as diferentes perspectivas num discurso de sustentação válida. Essa base nos parece nesse momento advir das filosofias fenomenológicas e existenciais, porquanto são aquelas que contemplam a dupla dimensão do sujeito, enquanto ser objetivo e ser subjetivo.

Cada ciência ou área de conhecimento com alcance delimitado no estudo de um mesmo objeto é o enredo que constrói o cenário das distintas espacialidades dos territórios. O destaque da geografia no estudo do território, dentre as outras áreas de conhecimento, pode ser atestado pela natureza mesma de sua abordagem. O conhecimento geográfico é sempre um conhecimento plural. De acordo com Amorim Filho,

A atividade geográfica, desde as suas origens mais remotas, sempre foi pluralista tanto em sua temática, quanto em suas abordagens (....). Apesar dessa pluralidade, a atividade geográfica sempre possuiu, para os geógrafos mais conscientes, uma unidade que, ao 
contrário do que alguns possam pensar, não é dada por nenhuma grande teoria ou orientação ideológica, mas sim, por certos objetivos e princípios gerais, em relação aos quais sempre houve certo consenso (explícito ou tácito) entre os membros mais coerentes da comunidade dos geógrafos. (AMORIM FILHO, 2007. p. 15)

Apesar de não se pautar por "nenhuma grande teoria", mas sim por "objetivos e princípios gerais", em meados do século XX, no pós-guerra, ocorre uma tentativa de unificação da geografia em torno de teorias exclusivistas ou ideológicas que culminaram posteriormente em "intolerâncias e tiranias paradigmáticas" (AMORIM FILHO, 2007, p.23 e 24), mas que se mostraram posteriormente deficientes quando confrontadas com a complexidade das realidades empíricas afloradas no contexto da pós-modernidade. É nesse contexto, afirma Amorim Filho, que vão aparecer correntes epistemológicas alternativas mais coerentes com os valores permanentes como é o caso da corrente denominada humanística (ou humanista) e o extraordinário renascimento e prestígio atual da geografia cultural. (AMORIM FILHO, 2007, p. 24). É com esta corrente que este trabalho irá dialogar mais de perto ao estudar os territórios sagrados de matriz africana em Contagem.

A geografia cultural reassenta a atividade geográfica em seu eixo central de articulação, que é a existência humana sobre a face da terra, resgatando e preservando, desse modo, a natureza plural do conhecimento geográfico, (Amorim Filho, 2007). Para Besse, "a Geografia não leva em consideração a natureza, mas as relações dos homens com a natureza, relação existencial, que é, ao mesmo tempo, teórica, prática, afetiva, simbólica, e que delimita justamente o que é um mundo." (BESSE, 1990, p. 139 apud AMORIM FilHo, 2007, p. 25). É a partir do ser humano situado num mundo concreto (físico) e significado por ele, portanto, num mundo simbólico (cultural), que o fazer geográfico se realiza. Esta mesma centralidade também é afirmada por Carl Sauer quando afirma que "a geografia cultural se interessa [..] pelas obras humanas que se inscrevem na superfície terrestre e imprimem uma expressão característica. (SAUER, 2003 p.22). Tendo isso como pressuposto, esta pesquisa buscará compreender o espaço e território sagrado das comunidades religiosas de matrizes africanas como espaços vividos, significados e valorizados a partir de seu universo simbólico sagrado.

Uma vez que a noção de território implica em saber onde está um grupo ou determinado sujeito e qual o alcance de sua presença a partir desta posição, podemos dizer que a primeira área de influência das ações de um determinado grupo é o seu território. Sendo assim, por territórios sagrados, entende-se, neste trabalho, a área de atuação de uma denominação religiosa específica, no caso aqui, as denominações religiosas de matrizes africanas, definidas como Candomblé e Umbanda. 
O candomblé e a umbanda são consideradas religiões de matrizes africanas por conter elementos e símbolos específicos que apresentam uma síntese resultante do processo de sobrevivência e de autopreservação cultural dos africanos escravizados no Brasil. (GóIs, 2008, p. 92). Por sua vez, o termo "religião" será entendido, neste texto, como as práticas ritualísticas que organizam a experiência de sentido ou significam a vida das pessoas que integram os grupos aqui estudados. Por área de atuação, na sequência, compreendem-se os espaços sagrados dessas religiões enquanto lócus específicos para realizações de suas cerimônias e rituais religiosos, ou seja, os "Terreiros" e "Centros", onde os objetos sagrados são guardados e o sagrado, propriamente dito é reverenciado.

Entretanto, as religiões de matrizes africanas pela natureza de seus rituais têm seus espaços sagrados expandidos para além dos locais fixos de suas práticas religiosas, englobando áreas naturais tais como matas, rios, cachoeiras, lagoas, estradas de terra dentre outros, que se transformam no momento de sua utilização numa extensão dos espaços sagrados restritos dos Terreiros e Centros. As oferendas, os trabalhos de limpeza de corpo, por exemplo, realizados nos espaços sagrados restritos dos Terreiros de Candomblés, precisam depois ser "despachados" em lugares específicos da natureza, tais como os mencionados acima. De outro lado, alguns Zeladores de Centros de Umbanda entrevistados afirmaram que certos rituais eram feitos na cachoeira ou nas matas. Na seção seguinte será apresentada a constituição territorial dessas comunidades a partir da extensão de seu espaço sagrado através da utilização compulsória de certas áreas como exigência inerente de seus rituais.

\section{A GEOGRAFIA RITUALÍSTICA DOS TERREIROS: \\ território e espaço sagrados expandidos.}

O local onde os adeptos do candomblé se reúnem e realizam seus rituais sagrados é denominado de "Terreiro"; por sua vez, o local dos adeptos da umbanda é denominado de "Centro". Todavia, enquanto o primeiro se refere a todo o terreno que circunscreve o salão, denominado de "barracão", onde efetivamente ocorrem as cerimônias, devido às "casas de santo" espalhadas pelo terreno, o segundo refere-se apenas ao ambiente onde ocorrem as cerimônias, normalmente uma sala ou salão mais amplo tendo ao fundo um altar com imagens de santos católicos, imagens de um velho escravo (preto velho), de índios e boiadeiros (caboclos), conforme observações durante a pesquisa.

Os atos litúrgicos dessas religiões se estendem para além de seu local, ou seja, o Terreiro e o Centro. Estes locais estendem-se, às vezes, por muitos quilômetros além deste espaço. Esta ampliação territorial decorre, primeiramente, da busca de um lugar 
na natureza, onde possam fazer suas oferendas. Este lugar pode ser um rio, uma cachoeira, uma lagoa, uma mata, dentre outros, que, uma vez encontrado, apresentase como um continuum, isto é, uma extensão do terreno onde elas se encontram.

Os atos religiosos dessas religiões ocorrem principalmente no espaço sagrado do Terreiro, mas algumas oferendas, com mais frequência no candomblé que na umbanda, precisam ser levadas para fora dessa área, dependendo do objetivo do ritual. Assim, por exemplo, se o propósito é oferecer um "presente" para o Orixá "Iemanjá" ou para a Entidade "Marujo" ou "Marinheiro", certamente, o local mais apropriado será na praia à beira-mar. No caso da ausência ou distância muito grande, a oferenda é feita no rio ou lagoa mais próxima, se assim for do agrado da Entidade reverenciada. Desse modo, os locais utilizados para além do Terreiro, irão depender da Entidade para a qual ela é realizada.

Nessa pesquisa, de acordo com a indicação dos Zeladores, o local mais utilizado, além do local de culto, é a Cachoeira (80\%), seguido das Matas com (72\%) e das Lagoas com (50\%). Talvez pela distância ou dificuldade de usar o local aparece com menor intensidade o Mar (Praia) e os Rios (8\%), Cemitério e Igreja (5\%) e, finalmente, Pedreira e Cruzeiro (3\%), como mostra o gráfico a seguir.

As Cachoeiras, as Matas e as Lagoas, foram mencionadas em quase todos os terreiros pesquisados. Todavia, os Cruzeiros, Pedreiras, Igrejas e Cemitérios, tiveram quase que a exclusividade de indicação na Umbanda e no Omolocô. As indicações de Pedreira e Cruzeiro que aparecem na tabela foram da umbanda; as de cemitério foram do omolocô e, finalmente, as de Igreja, uma foi do omolocô e a outra do candomblé. No entanto, esses locais encontram-se cada vez mais escassos na medida em que os municípios vão sendo urbanizados.

A escassez de áreas verdes próximas aos terreiros pode ser ainda mais acentuada se for levado em consideração que essas áreas podem ser privadas ou de uso público restrito. Todavia, dada a localização dos terreiros e os lugares onde se encontram as áreas verdes, os candomblecistas e umbandistas têm que se deslocar cada vez mais longe em busca de locais apropriados para alguns de seus rituais. Para se ter uma noção desse deslocamento, foi medida a distância entre a cidade de Contagem e os outros municípios indicados como lugares onde os praticantes dessas religiões se deslocam para fazer suas oferendas. Esses lugares são procurados porque têm os locais apropriados para as oferendas e são escolhidos em função da distância e do acesso aos mesmos. A Figura 1 mostra a distribuição do uso desses lugares conforme o tipo de local que se procura ou deseja para as oferendas. 
Figura 1 - Representação espacial da distribuição dos municípios dos locais de oferendas dos Terreiros de Contagem, MG (2009-2010)

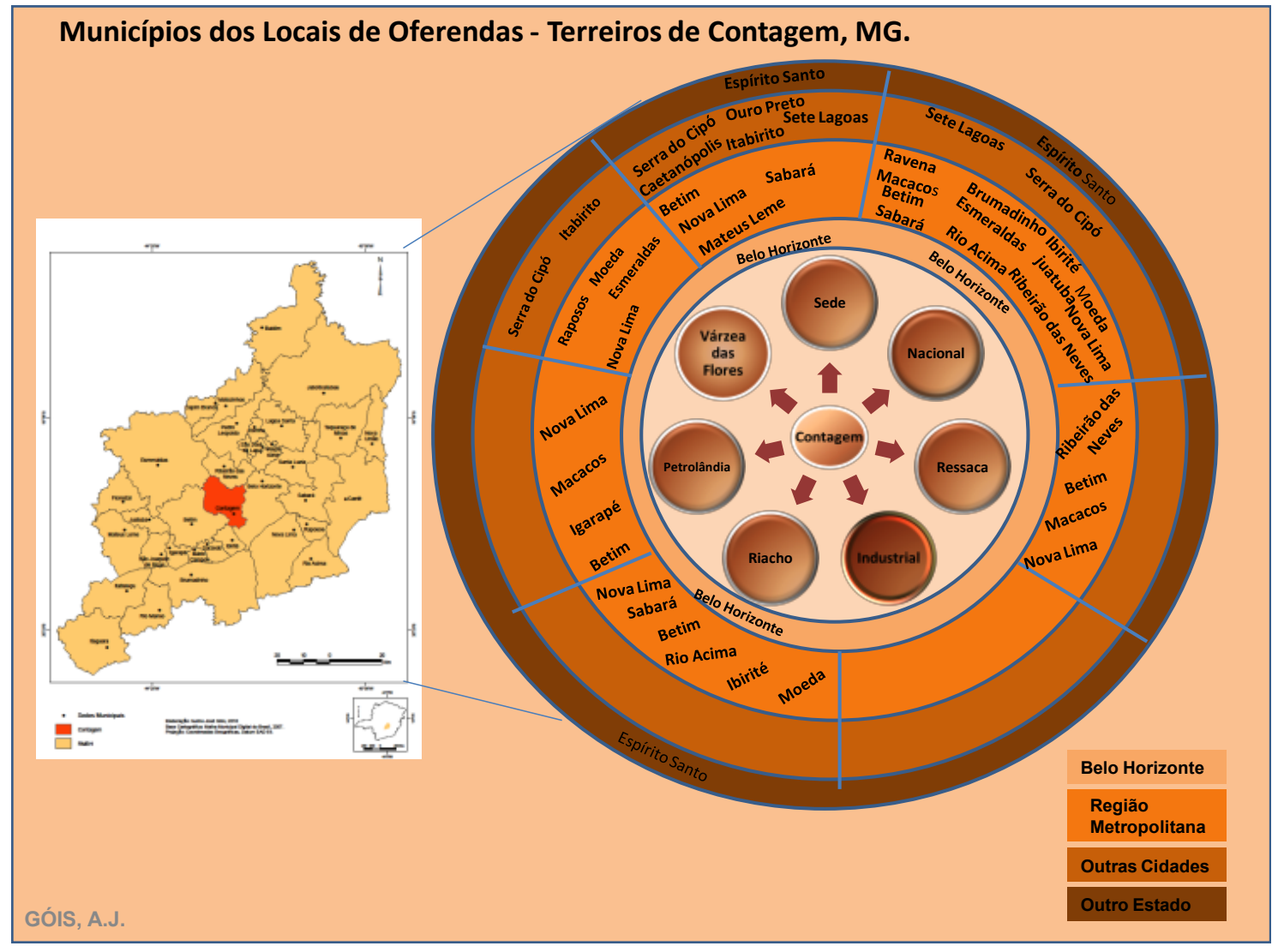

Fonte: Dados da pesquisa

Os anéis da Figura 1 mostram que a expansão territorial dos espaços sagrados dos terreiros se estende para além da região metropolitana da cidade, penúltimo anel, chegando até outro Estado da União, último anel de cor mais escura. Entretanto, o maior deslocamento ocorre na região metropolitana, anel mais alaranjado.

$O$ ideal para os Terreiros seria encontrar um lugar que reunisse todos os locais necessários para suas oferendas, ou seja, que tivesse cachoeira, lagoa e mata - lugares mais procurados, segundo revelou a pesquisa. Os municípios que mais atendem a essa expectativa são: Contagem, Betim e Moeda, com mais de 40\% de procura, seguidos de Belo Horizonte, Macacos e Nova Lima, com aproximadamente 20\% de utilização, Ribeirão das Neves, Ibirité, Sete Lagoas e Esmeraldas, com 11\% de uso, Itabirito, Sabará, Serra do Cipó, Rio Acima e o Estado do Espírito Santo, com 8\% e, finalmente, Juatuba, Ravena, Brumadinho, Raposos, Ouro Preto, e Caetanópolis, com $3 \%$ deprocura.

Os terreiros que se encontram em áreas mais urbanizadas que não tenham próximo a eles áreas verdes disponíveis para levar as oferendas, certamente, fazem um deslocamento maior em relação àqueles que se encontram próximos aos locais 
propícios. Um maior deslocamento implica em mais gastos materiais. Assim, na medida em que escasseiam as áreas verdes de acesso público, mas os terreiros terão dificuldade em realizar seus rituais, na medida em que precisam se deslocar cada vez mais para lugares mais distantes. Para se ter uma ideia da média atual de deslocamento dos terreiros analisados nessa pesquisa, a figura a seguir mostra a distância, em relação a cidade de Contagem, dos municípios indicados pelos Zeladores para suas oferendas. Essa distância foi obtida através da ferramenta Google Maps - para uma melhor representação gráfica, algumas medidas foram aproximadas para mais e outras para menos.

\section{DISTÂNCIA DOS LUGARES UTILIZADOS PARA OFERENDAS EM RELAÇÃO À CIDADE DE CONTAGEM, MG}

Figura 2 - Representação espacial da distância dos municípios dos locais de oferenda dos Terreiros, em relação à sede da cidade de Contagem, MG (20092010)

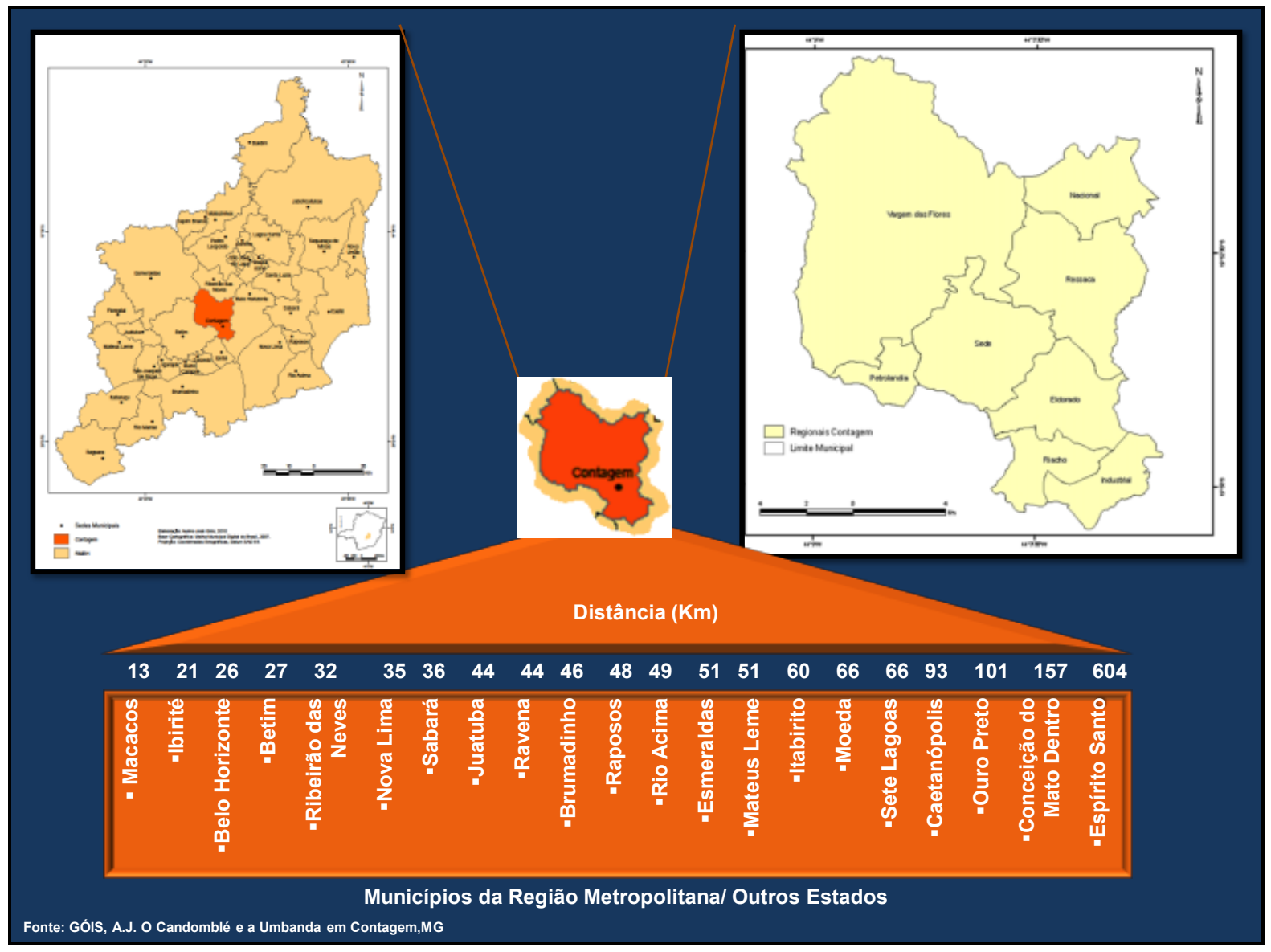

Fonte: Dados da pesquisa

Conforme mostra a figura acima, os terreiros percorrem uma distância que varia entre 13 a 600 quilômetros para a realização das oferendas ou em termos 
médios, dividindo a soma dessas distâncias pelo número de municípios implicados, pode-se afirmar que cada terreiro percorre em média 80 quilômetros aproximados para realização de alguns de seus atos litúrgicos que, devido a essa especificidade, exige uma ampliação territorial de seus espaços sagrados.

A exigência de ampliação territorial dos terreiros de umbanda e candomblé inerente aos seus rituais sagrados torna-se um problema para essas religiões, na medida em que o local onde se encontram instalados vai se urbanizando, como ocorreram com os terreiros instalados em Contagem a partir da década de 1960 com a criação da cidade industrial. Desde então, Contagem aumenta exponencialmente a sua população e densidade demográfica. Em 1960 sua população que era de 27.914 habitantes atinge em 50 anos 603.442 habitantes, segundo o censo de 2010 (IBGE, 2011). Esse aumento populacional vertiginoso está relacionado com o fluxo migratório de trabalhadores do interior e de outros estados atraídos pelas novas oportunidades oferecidas pela industrialização da cidade. É com essa leva de migrantes que também chega à região o candomblé, nessa cidade.

Com a urbanização dessa cidade, as áreas utilizadas para oferendas ou são eliminadas, normalmente para a construção de empreendimentos imobiliários, ou são cercadas por seus proprietários para coibir as invasões, proibindo assim o acesso a elas. Uma nova paisagem é desenhada e essas religiões, antes instaladas num ambiente favorável, encontram agora dificuldades para a realização de seus rituais, conforme demonstrou a pesquisa (GOIS, 2011). Uma das principais dificuldades é a convivência com a nova vizinhança, sobretudo a vizinhança de pertença às igrejas evangélicas. Oitenta por cento dos terreiros pesquisados apontou algum tipo de conflito com essa vizinhança (GoIs, 2011 p.155-161). Esse tipo de conflito não é algo particular dos terreiros de candomblé e umbanda de Contagem, mas das religiões de matrizes africanas em todo o território nacional, fenômeno este estudado com propriedade, dentre outros, pelo pesquisador Vagner Gonçalves da Silva (2007). Este texto, no entanto, limitou-se a analisar a dificuldade imposta aos terreiros pelas mudanças no ambiente natural.

\section{CONSIDERAÇÕES FINAIS}

Apesar do candomblé e da umbanda serem religiões urbanas, elas não prescindem dos recursos naturais, uma vez que o sagrado que elas cultuam, os Orixás e Caboclos, são energias ou forças ligadas à Natureza, tais como rios, cachoeiras e florestas, dentre outros locais, em que cada uma dessas divindades 
sagradas operam. Por este motivo, o Terreiro estende seu território para além do terreno onde se encontra instalado. Esse alcance territorial alcança seus limites nos espaços da natureza utilizados para as oferendas inerentes aos ritos religiosos. A expansão territorial do espaço sagrado, através do uso de áreas externas para oferendas, não é uma ação esporádica, mas constitutiva dos eventos litúrgico-religiosos dessas religiões. Talvez isto explique porque a distância, embora possa oferecer dificuldades para a realização das oferendas externas, tais como o custo financeiro e a disponibilidade dos adeptos, devido a suas ocupações profissionais, não chega a ser um impedimento para a realização dessa exigência ritualística. Esse aspecto denota a fé e devoção dessas religiões para com suas divindades protetoras e revela o forte acento da dimensão comunitária dessas religiões, uma vez que essas oferendas mobilizam tanto os integrantes do terreiro quanto as pessoas que se relacionam com a Comunidade religiosa, mas não têm, para com ela, nenhum tipo de compromisso mais efetivo, conforme apontou também a pesquisa.

Uma vez encontrado esses locais, eles são vinculados ritualisticamente ao Terreiro, estabelecendo uma continuidade espacial entre ambos, no momento em que é utilizado para alguma oferenda. Desse modo, o ambiente natural em torno do Terreiro transforma-se em espaço sagrado através dessa vivência ritualística. A extensão desse ambiente será uma razão direta da distância entre o Terreiro e os locais na natureza onde se encontram in natura as energias cultuadas, determinando a espacialidade geográfica de seu rito.

A impossibilidade de expandir territorialmente o espaço sagrado do terreiro pode vir a inviabilizar ou dificultar em demasia a manutenção de alguns atos litúrgicos importantes, podendo mesmo levar à sua extinção no futuro, a exemplo da "Macaia”, um ritual realizado na mata com os caboclos. Segundo um dos Zeladores entrevistados, a "Macaia", não pode mais ser feita porque não tem mais mata e nem segurança para tal evento. Na verdade, esse fato narrado pelo Zelador entrevistado aponta um dos efeitos das múltiplas relações da religião com a sociedade, a cultura e o ambiente, tarefa de que se ocupa a geografia da religião (GIL FILHO, 2008 p. 12).

Nesse sentido, essa pesquisa aponta para a necessidade de preservação, manutenção e acessibilidade aos locais de oferendas, supracitados, podendo vir a se constituir, no futuro, em uma política pública a ser pensada no Município em função da preservação do patrimônio imaterial dessas religiões. Sendo assim, um diálogo precisa ser estabelecido com o poder público, para que os adeptos dessas religiões efetivem o seu direito de culto que pode vir a ser, no futuro, impossibilitado por um processo de urbanização não inclusivo. 
Essa pesquisa parece assinalar para a necessidade futura, senão imediata, de se pensar uma urbanização que contemple o direito à cidade dos cidadãos religiosos de matrizes africanas no contexto urbano das grandes cidades do país. Para isso, é preciso antes compreender e considerar o território como "multidimensional", ou seja, que comporta uma multiplicidade de ações que resultam em distintas espacialidades (SAHR, 2007, p.59). Para tanto é preciso negociar (VARGAS, 2007, p. 166), pois ele pode ser apreendido tanto na expectativa de uma espacialidade em particular, quanto na expectativa de espacialidades múltiplas. O que esta pesquisa apresenta é a espacialidade particular do território sagrado dos terreiros de candomblé e umbanda como uma das espacialidades a ser considerada na compreensão dos territórios urbanos.

\section{REFERÊNCIAS}

AMORIM FILHO, Oswaldo Bueno. A pluralidade da geografia e a necessidade das abordagens culturais. In: KOZEL, Salete, SILVA, Josué da Costa e GIL FILHO, Sylvio Fausto (Orgs.). Da Percepção e Cognição à Representação: reconstruções teóricas da geografia cultural e humanista. São Paulo: Terceira Margem; Curitiba: NEER, 2007.

FUNDAÇÃO JOÃO PINHEIRO - FJP. Produto Interno Bruto de Minas Gerais. Informativos Cei, terça 16 de junho de 2009. Disponível em:

http://www.fjp.gov.br/index.php/servicos/81-servicos-cei/58-produto-interno-brutode-minas-gerais. Acesso em: 6 nov.2010.

GIL FILHO, Sylvio F. Espaço Sagrado - estudos em geografia da religião. Curitiba: Ibpex, 2008.

GOIS, A. J. O candomblé e a umbanda na cidade de Contagem, Minas Gerais (2009-2010) - Espaço e Território. 2011. 152 f. Tese (Doutorado)- Pontifícia Universidade Católica de Minas Gerais, Programa de Pós-Graduação em Geografia Tratamento da Informação Espacial, Belo Horizonte, 2011.

GOIS, Aurino J. O diálogo inter-religioso entre o cristianismo e as religiões afrobrasileiras. In: AMÂNCIO, I.M.C (Org.). África-Brasil-África: matrizes, heranças e diálogos contemporâneos. Belo Horizonte: Nandyala, 2008.

INSTITUTO BRASILEIRO DE GEOGRAFIA E ESTATÍSTICA. Cidades. Disponível em: <http://www.ibge.gov.br/cidadesat/topwindow.htm?1>. Acesso em: 22 jul. 2011.

LAUDARES, Sandro. Aplicações em sistemas de geo-visualização: uma proposta metodológica a partir de componentes WEB genéricos. Belo Horizonte: Pucminas/ Geografia - Tratamento da Informação Espacial, 2007 (Tese).

PREFEITURA DE BELO HORIZONTE - PBH/ Secretaria Municipal de Cultura/Ministério da Justiça - Fundo de Direitos Difusos. Belo Horizonte, 2003. Disponível em:

<http://portal5.pbh.gov.br/fan/iniciaBemCultural.do?id=196\&method=searchFast $>$. Acesso em: 25 set. 2008. 
ROSENDAHL, Zeny. Espaço e religião: uma abordagem geográfica. Rio de Janeiro: Eduerj, 2002.

SAHR, Wolf-Dietrich. Signos e Espaço Mundos - A semiótica da espacialização na geografia cultural. In: KOZEL, Salete, SILVA, Josué da Costa e GIL FILHO, Sylvio Fausto (Orgs.) Da Percepção e Cognição à Representação: reconstruções teóricas da geografia cultural e humanista. São Paulo: Terceira Margem: Curitiba: NEER, 2007.

SANTOS, Jocélio T. dos. Mapeamento dos terreiros de Salvador. Salvador: CEAO/UFBA, 2008.

SAUER, Carl O. Geografia cultural. In: ROSENDAHL, Zeny e CORREAA, R.L. (Orgs). Introdução à geografia cultural. Rio de Janeiro: Bertrand Brasil, 2003.

SILVA, Vagner Gonçalves da. (Org.). Intolerância religiosa - impactos do neopentecostalismo no campo religioso afro-brasileiro. São Paulo: Edusp, 2007.

VARGAS, Icléia A. de. Paisagem, Território e Identidade: uma abordagem da geografia cultural para o pantanal Mato-Grossense. In: KOZEL, Salete; SILVA, Josué da Costa; GIL FILHO, Sylvio Fausto (Orgs.). Da Percepção e Cognição à Representação: reconstruções teóricas da geografia cultural e humanista. São Paulo: Terceira Margem; Curitiba: NEER, 2007. 